and Murphy, and I think we must all take them as a joke. Dr. Ferguson has insisted on saying that this is the Mayo operation. My own feeling is that all this stuff about priority is bosh. I have no doubt that this operation was done by Hippocrates; he was a very sensible old fellow and quite likely, as they get in deeper in the Egyptian ruins, they will find that this operation was performed by the inhabitants several thousand years ago.

\section{REPORT ON OPERATIVE TREATMENT OF GRAVES' DISEASE.*}

\section{T. C. WITHERSPOON, M.D.}

ST. LOUIS.

CASE 1.-In April, 1895, a patient presented herself for treatment suffering from a well-developed Graves' disease. Exophthalmia was not marked, but the cardiac frequency and the thyroid enlargement was present. Tremor, loss of flesh and bowel symptoms made the case one of undoubted Graves' disease. She submitted to partial thyroidectomy under chloroform and made a nice recovery. Two years afterward I received word from her through a friend that she was well and strong, able to attend her duties and suffering none of the former symptoms.

CASE 2.-In 1898 a patient was sent me who suffered from a similar condition. She was 52 years of age, very thin, having lost a great many pounds of flesh, suffered from recurring diarrhea and was very weak, practically bed ridden. The pulse rate was 140 to 160 , the thyroid very large and vascular, exophthalmia not marked. The right lobe being the larger was removed under cholorform anesthesia. There was very free hemorrhage from the inferior thyroid, and on account of pulse weakness she was given a pint of saline under the skin while on the table. This was repeated in two hours. Within six hours the pulse had regained the rate and quality which characterized it when she went on the table. During the night it began to increase in rate and lose in strength. There was no response to stimulants and in forty-eight hours she died.

CAsE 3.-The third case on whom I operated was a woman 59. years of age. She was born in Missouri and had lived in St. Louis for many years. Her first visit to me was in September, 1899 , at which time she suffered from very evident Graves' disease. The goiter was well marked, the right thyroid lobe being the larger, there was moderate exophthalmia and the pulse rate was from 130 to 150 . She had lost a good deal of flesh, the skin was always moist because of an ex. hausting sweating, the nervous symptoms were marked, heard strange noises and had ideas of persecution; the respiratory movements were extremely shallow and pectorals wasted, bowels were diarrheic, urine contained casts and albumin, and was slightly increased in the 24 hour amount. A diagnosis was made of chronic interstitial nephritis associated with Graves' disease. I was of the opinion that her general condition contraindicated so extensive an operation as partial thyroidectomy and advised a double sympathectomy. Septem. ber 10 the three ganglia on the right side were removed and on the 2lst those of the left, under chloroform. The healing was primary and shortly after the second operation the pulse showed improvement in quality and rate. Her general condition was likewise benefited, the bowels ceased to become overactive, the sweating stopped, the weight improved. December 14 she had so far recovered that she took a trip into the country to take advantage of the fresh air and outdoor life possible there. From her son I learned later that in the latter part of the month of February while out riding she became chilled and died two hours afterward. He states the pulse rate had become normal before her death, the exophthalmia had almost entirely disappeared and the goiter fully half. Her mental condition was normal and the nervous symptoms had cleared up to a large extent. What part was

* Read at the Fifty-fourth Annual Session of the American Medical Association, in the Section on Surgery and Anatomy, and approved for publication by the Executive Committee: Drs. A. J. Ochsner, J. E. Moore and De Forest Willard. played by the nephritis in her sudden death can, of cou be only a matter for conjecture, but it must be admitted operation-was followed by decided relief.

During the last twelve months I have had a series six cases presented me for operation in all of whid partial thyroidectomy was performed. They were follows:

CAse 4.-About the first of May, 1902, S. S. was sent to with a pronounced exophthalmic goiter. She had been und treatment without benefit and an operation was advised. was born in Germany, came to $\mathrm{St}$. Louis when 16 years age, and has lived here since, a period of 23 years. Ther nothing of note in her family history. At the time of her pregnancy the thyroids beeame larger and remained so arfin ward. There were no symptoms of Graves' disease until abou a year before $I$ first saw her. At that time she noticed an in creased nervousness and rapid heart action. At the time the examination she had a well-marked exophthalmia and stat that the intensification of the symptoms dated back five month at which time she became pregnant. Her general condity indicated a process of only moderate severity. There was a great loss of flesh and her appetite and strength were. She did suffer from a marked degree of nervousness, howe 100 and insomnia was distressing. The pulse rate varied from to 120 , exophthalmia marked, Graefe symptom present, right thyroid lobe the larger. Other symptoms were presegh as tremor, sweating, headache, recurring diarrhea. these had had attacks which resembled asthma for years, and thes had been intensified.

May 6 the right lobe was removed under local anesthesis After finishing the operation and while putting on the dre ing she had a slight tetanic attack, general in character No accompanied with a loss of consciousness for the moment. Felt ill effects followed this, and after being placed in bed she felt quite easy, except for a mild degree of burning in the area the wound. This lasted only two hours and disappeared. The improvement in her condition was apparent in two days, within the next week she was fairly free from nervouspes. The pulse dropped to 74 in forty-eight hours. There pur rapid improvement in the exophthalmic condition also. Du ing the remaining time of pregnancy she showed only de symptoms as are characteristic of the period. She was livered at full time of a healthy child, making a nice ${ }^{\text {to }}$ covery herself. At the present writing her condition is $q^{\text {uit }}$ normal.

CASE 5.-Mrs. B. came to me in June presenting the follor ing history and conditions: Born in St. Louis, lived here her life, 35 years, parents were German, she was married solvio years, but had no children; examination revealed no pelv disturbance. Gives no family history which could shed lighe on her trouble. About nine months before coming to me sh noticed the first marked symptoms of her present disease, though for some months prior to that time she had noticed increased nervousness and a tendency to tremble when the hands. I found on examination well-developed thyrois. larger on right side, pulse varied from 120 to 130 , exop thalmia marked and Graefe and Moebius symptoms demonstrable. The other symptoms were present, tremor, the hands, diarrheas, sweating, loss of flesh, sleeplesspess easily excited, headaches, dry hair coming out in rather 10 ro quantities. The right vessels gave both a distinct bruit. interesting feature was the pronounced prominence of the lot eye.

The right lobe was removed under local anesthesia and bet terment of the condition immediately followed. At the presthe time all of the old symptoms have disappeared, including exophthalmia. She has gained in flesh and feels well.

CASE 6.-In July I removed the right thyroid lobe of a $p^{2}$ tient in one of the city institutions. She presented the symptoms and had in addition a movable right kidney slight uterine prolapse. After the operation she made rapid recovery, sleeping well, no tremor and gaining strength. After leaving the institution I lost track of her. 
COSE 7.-Mrs. W., age 62, born in Switzerland, lived in St. There eighteen years, was sent to me in July for an operation. daughter no family history of importance except that a goiter of 36 years of age has at the present time a simple which. She had a goiter herself for twenty years, during 8rmptime there was no indication of trouble from it. The of ptoms of Graves' disease dates from the time of the death culosis child three years ago. This daughter died of tubermonis. In January, 1902, she suflered an attack of pneuthe left from which she did not fully recover. Effusion into The left pleura followed it and on May 17 three pints of this the removed. Again on the 27 th this was repeated, removing ported amount. The physician in charge at the time reported on the character of this fluid, stating it was not purfound nor bloody. The expectorate was likewise examined and tomg to contain no tubercle bacilli. At this time the sympmark of Graves' disease became very pronounced. The tremor marked, muscular weakness with emaciation sufficient to pulse her to remain abed, insomnia, emotional perturbations, pulse varying in rate from 135 to 160 , and frequent diaruless attacks. The exophthalmia was not readily noticed The attention was called to it.

The right thyroid lobe was the larger, and this one was rethe July 20. It had grown downward into the chest behind te sternum and was adherent to the trachea for a short inthrol. The vessels were very friable and the forceps pinched ing the inferior thyroid during the operation and bleedwhich became very active. This necessitated a haphazard catch, Which included the inferior (recurrent laryngeal) nerve. ImDediately a fluttering vocal cord was the result. In tying the arated after stopping the hemorrhage it was carefully sep. afted from its surroundings. The voice returned very slowly afterward, never to its normal quality. A pneumonia was set seat, which appeared on the fifth day in the left lung, the eat of the former attack. Eventually this subsided in part and the patient began to improve. A careful examination still tom to reveal tuberculosis. In six weeks the nervous symp. bet had nearly disappeared and the rate of heart action was theen 90 and 100 . There was a slight, constant fever and cough and the fluid reaccumulated in the side. On aspiration iis was found to be purulent. An operation was strongly adlost, but refused until late in October. By this time she had and the flesh gained just after the operation on the thyroid a was very weak. The process had extended to the lung and large quantity of stinking pus was being expectorated conantly. A portion of rib was removed under local anesthesia abd a drain established. She never rallied, however, and died thout Christmas last. There was a complete disappearance of Gro symptoms which were distinctly characteristic of the Traves' affections before her death.

$\mathrm{C}_{\triangle 8 E} 8 .-\mathrm{A}$ widow, aged 44 , born in Germany, came to $\mathrm{St}$. Guis 16 years ago. She has one living child healthy. She gives no history of former trouble which could bear on the Present trouble except that 18 years ago she contracted a penereal disease from her husband which confined her to the lospital for several months. The cervix of the uterus is entirely gone and a small opening in the midst of scar tissue is the os uteri. Menstruation is normal except scant in amount. She gives no history of syphilis. Her pulse varied from 95 to lio, some degree of exophthalmia, goiter goose egg in size, the right lobe the larger. A fine tremor, muscular weakness, diarrhea, sweating, nervousness, sleeplessness, headaches were present. I removed the right lobe of the thyroid in September. The pulse rate became normal after the operation, the general condition improved and the tremor left. She still suffers, howeper, from headache, fullness in the throat and complains of dition in the pelvis. This, I believe, is due to the uterine con-

CASE 9.-Just operated on. Patient is 20 years of age, born in Kansas, and has lived in various parts of the country during the last ten years. Of herself she writes the following antory, and because of its exactness $I$ give it in full. Rather anemic looking since fifth year, scrawny shoulders and small arms. All through life frequent headaches in forehead. In sixteenth year moved to Colorado, living in altitudes of from
6,000 to 9,000 feet, where was employed as a railroad clerk for three years. Felt well greater part of the time. Eyes would occasionally become inflamed; riding on trains augmented this trouble. Vision was not impaired for three years after first inflammatory attack. About twentieth year moved to Mem. phis, Tenn., eyes becoming more often sore. Oculist advised against glasses and used some drops in eye for two months daily. Vision now became impaired, objects blurred, lines of type ran together. Saw another oculist, who fitted glasses, said trouble was flattened cornea. Wore these glasses with. some relief for about a year, eyes gradually becoming worse; inflamed with imperfect vision. In twenty-fourth year another oculist fitted glasses, saying the trouble was compound myopic astigmatism with the consequent inflammation. Great relief followed; worn the glasses since with improved vision, inflammation lessened. Past three years has had many spells of aching back of left eye and followed by reddened conjunctiva. About the twenty-fourth year hand became unsteady when writing. During the summer months each year while in Memphis got debilitated and irritable. During the winter of the twenty. fifth year worked all day and until 11 o'clock at night. Kept up by large quantity of alcoholics. In spring of same year, 1899 , passed first-class examination for old line life insurance. No enlargement of neck was noted at the time. Pulse was a trifle quick, attributed to running up stairs. During the summer became gloomy, brooded over unfair treatment thought she had received at the office where working. Spent month of July in St. Louis, read much pessimistic and agnostic literature. Thought a great deal about suicide, did not contemplate suicide, but the subject was more attractive than others. Returned to Memphis August of the same year in the same state of nind. Friends tried in every way to divert her mind into new channels without success. Again worked hard the fall and winter of the twenty-sixth year. Gradually mind became normal. December, 1899 , noticed neck seemed to look too full in front, friends thought it was all right. In winter was tired all the time, sore and ached all over on awakening; very nervous and irritable. Hands and feet became swollen and red, burned and itched when taking exercise. For last three years perspired profusely on slightest exertion. Hands and face would be moist and clammy while those about were dry and comfortable. Did not sweat at night when quiet in bed. Hair became faded and dry, but did not fall out to any appreciable extent. During the summer of 1900 lost much flesh and became more nervous and weak. In the fall some improvement.

About Jan. 1, 1001, noticed rapid heart action and shortness of breath. Remained in bed for a part of February complaining of prostration, nervousness and insomnia. At this time the goiter became quite perceptible. Dr. R. Maury prescribed tr. iodin applications without benefit to the goiter. Massage was then resorted to for a month with no benefit. If anything this last increased the nervousness. The professor of nervous diseases at the Memphis Medical College then preseribed Norwoods tincture of veratrum viride, to be taken constantly and a mixture of hyoscyamus, potassium bromid and chloral to quiet. This latter was taken at bed time for two years. For the remaining time the bromid alone has been used to produce sleep ( 60 to $100 \mathrm{grs}$ ).

Exophthalmia was noticed in June, 1901. At this time she gave up all stimulants, as they caused a sense of weakness and she had to go to bed after taking them. Later in same summer went to Lake Superior for a visit and improved remarkably, gaining 18 pounds. In fall relapsed into old condition on returning south. Complained at this time of having both knees give away while walking, causing her almost to fall at times. Arms and legs became numb after resting in one position for a while. Last summer spent at Put-in-Bay, but an exhausting diarrhea prevented improvement.

In fall went to Colorado, where nervousness and rapid heart increased and mental condition became worse than ever. Had maniacal spells, screamed, tore clothing and refused to remain in the room with any one. Physician in charge gave thyroids and strychnin, and if anything the symptoms were 
intensified. Pulse was frequently as high as 150 and felt like a pile driver in the neck. Thyroid increased in size. Took 400 grains of bromid in two hours to quiet. Later returned to the chloral mixture and a tonic. During the last three months suffered from alternating diarrhea and constipation. Appetite fluctuated from a craving for food to a distaste for it. Limbs twitched in bed and insomnia continued. Sore around body and hung clothes from shoulder; temperature of 99 to 100 in the late afternoons. Has a cough which developed in December, 1901, and has continued more or less ever since. At menstrual periods the gland seems to become turgid and causes a sense of choking from pressure.

The only family history which could bear on this condition is on the mother's side. She had asthma until her sixteentl year, always had an affection of the right side of the mouth and jaw. Right lobe of thyroid slightly enlarged and had been so from childhood. Never had the other cardinal symptoms of Graves' disease. Mother of seven children, three died in infancy; one son and three daughters are living. Son as a child suffered from nervous twieching, is now 40 and healthy; daughter, aged 32 , has writer's cramp at present, always nervous. Other daughter always free from nervousness. Mother in good health at present.

July 15, 1903.--This patient is in better health than for some time. Exophthalmia gone. Pulse 80 to 90 .

These cases of Graves' disease have been in the past most unsatisfactory to treat. Nearly every effort to bring about permanent relief has been fruitless. We have all seen temporary benefit follow the administration of different remedial agents, and have been at times tempted to believe that much of permanent character had been accomplished, only to be disappointed later when, after losing sight of the patient for a while, they would return in a more deplorable condition than ever. Failure in this disease has, as in many other maladies, led to the adoption of a host of remedies for its cure.

It is exceedingly interesting to follow the views of the various writers of the different decades on the subject, and note the changes in the methods of treatment. We read of the disease being a dyscrasia, then, again, a blood impoverishment expressing itself by changes in the thyroid, eyes and heart; later the opinion of alimentary intoxication, a sympathetic disease or a pathologic condition of the central nervous system located in the area of the pons or medulla. Of the recent authoritative writers Moebius adheres to the belief that the seat of the lesion is in the thyroid gland, while Kocher, of Berne, considers the thyroid condition an expression of a central lesion located in the cerebrospinal axis. Mention should be made of the work done by Gley, of Paris, showing a disturbed parathyroid relation with the thyroid as a possible cause of the disease symptoms. As from time to time new light has been shed upon the subject, bringing modified ideas of its pathology, the methods of treatment have accordingly been modified or changed altogether. Iodin, strophanthus, veratrum viride, bromids and chloral, galvanism, thyroid extract, adrenalin, sodium phosphate, sodium salycilate, dietetic regulation, massage, the serum of thyroidectomized goats, the flesh and milk of these animals, and lastly, various surgical procedures, have each been advocated as most helpful.

Naturally, the question arises, what are we to do for, how are we to relieve this class of patients when they coine to us for relief? Is there an underlying cause for the condition which can be attacked alike in each case, is there a procedure which could become universally applicable? In the light of our present knowledge we can not hold to too strict limitations, though no doubt were the exact nature of the disease known some rule of action would become applicable to all cases. At the present time a certain degree of empiricism must $e$ into the treatment; our conduct toward these cases rest to a large extent on our experiences in the past. must notice where the internist obtains good results, weigh carefully the data he presents; likewise have to consider the surgeon's side of the question, and ing here success and there failure, obtain an explang of the different results by the different manners of op tion, and the individual characteristics of the patien

I present here the results which I have obtained cases in which internal medicine failed to give $\mathrm{r}$ The outcome has been very satisfactory to me, and. helped very materially to lead me to the belief that cases are eminently surgical. Since reading Koch article, this belief has been confirmed, and I feel thusiastic in supporting proper surgical methods for relief of Graves' disease. Of course, do not unders this to mean that I advocate operation in every regardless of all conditions, local or general. first place, we must be governed by those rules are followed in advising operation on any part o body for the various conditions which fall to the geon's hands. In the second place the symptoms characterize Graves' disease must be given due consid tion, and proper value placed on the conditions characterize each individual case.

A number of surgical procedures have been propos The injection of agents into the gland which ten sho destroy its secreting power is dangerous, and. never be resorted to.

Ligation of the thyroid arteries to reduce vascu of the gland has a warm advocate in Kocher. method was recommended by Woefler for the com goitre, but Kocher put it to use in the exophthalmic riety. Rehn, Trendelenburg, Rydygier, Wilmers, bach and Mikulicz have reported cases treated in way. Ligation of the superior thyroid is relatively but the inferior can not be gotten at through an inci in front of the sternocleidomastoid, except by lux the gland upon the surface, in many of the cases selecting the ressels, attention will be paid to the am of vascular degeneration of the different parts of gland. It is rare that the whole gland is alike aftect Those vessels are ligated which best control the larity. The operation is simpler than removing lobe, and is to be recommended in those cases the symptoms remain intense after resting the pat Later, however, this procedure should be supplem by a partial thyroidectomy in the large percent of The initial ligation always renders the removal lobe easier than where this is done primarily.

Unquestionably, the operation which gives the gr est degree of satisfaction is the removal of the most volved lobe of the thyroid gland. Very frequently is the right. Why this should be so is difficult to stand. Many explanations have been given, but satisfactory. Two incisions are to be recommended, in front of the sternocleidomastoid parallel to its ant border, and the U-incision recommended by Kocher the convexity over the sternal notch. Kocher mends the latter because it allows easy access median line, where after separation of the muscles lie upon the trachea the thyroid lobe can be reached. This avoids cutting any of the muscles 0 neck. The scar is low and not readily seen. Perso I prefer the incision anterior to the muscle edge. length need never be more than 4 inches, and it the least bloody handling of the gland. The one o tion to the incision is that it necessitates the cuttin 
is incomers of the sternothyroid or the sternohyoid. This nearly through enough parallel to allow of separation directly or the their bellies, and only a few fibers of the one This other have to be cut at the ends of the incision. have had the field perfectly for the largest goitre I an had to deal with. The scar is small and located in less appomic position which to some extent renders it sparent.

capsule afe some precautions to be mentioned. 'The and gland vascular. In separating it from the enclosed This is very considerable amount of hemorrhage follows. perior avoided to a certain extent by ligating the suing thyroid artery first. Just under the muscles, comressel is above and entering the top of the gland, this bran is easily found. It frequently enters as several if the cult step trunk can not be gotten at. The next diffican onl is securing the inferior thyroid artery. This and only be done after raising the gland from its bed rascularying it toward the median line. The whole some pesparatus is so friable that it is possible that ing hard to size be torn in this separation and bleedabout to control. To render this less difficult, bring bleeding careful, gradual luxation, catching each ing and point with a forcep as it occurs. After reachremored ligating the inferior thyroid all forceps can be It is wis as these two vesesls supply the area with blood. forcipre to ligate. the large veins, however, for, though time, large their lumens are apt to open later and allow of a point in formation in the wound. A very difficult Pascul in the operation is catching hold of the highly it. $V_{u}$ gland with any instrument with which to hold on $\mathrm{Vu}$ cella forceps tear out and cause very serious hemsurface. I find it expedient after exposing the anterior silk from the gland, to pass heavy mattress stitches of catch $\mathrm{m}$ side to side, and when these are tied the forceps glandulter, and bleeding does not follow any little ing the laceration. Great care must be used in avoidinferior recurrent laryngeal nerve, while dealing with the This thyroid.

local anestherion should always be performed under ution anesthesia. Kocher recommends a 1 per cent. soPer centong the line of skin incision. I prefer a 0.125 Do pain solution. It is incorrectly staced that there is These after reaching the deep structures of the neck. by the patients, very nervous and strung to a high pitch in handlinghts of the operation, do complain of pain controlling the deep structures, and are more readily being led when the whole area is infiltrated. Eucain, be non-toxic when used in reasonable amounts, can is reely injected in very dilute solution. Infiltration the separtween the gland and its capsule just ahead of of the dration. I have never required more than $1 / 2$ gr. to reing drug to complete the entire operation. It is wise ound. not drail Aligatures are made with a fine silk: I have that the my cases. At one time there was a fear the pound secretion expressed during the operation into ouface and that formed and given off from the cut allope afterward were dangerously toxic. Drainage There these to escape, and therefore was recommended. be clo some danger from the bleeding into ation cosed wound afterward, this causing suppufour and septic symptoms. A twelve to twentybood of drain is allowable when there is likeiv.
Socin proposed the excision of enlarged nodes. This is not to be recommended, as it is incompetent and bloody, and many thyroids are uniformly degenerated. The Mikulicz operation, proposed for the ordinary parenchymatous goitre, has been resorted to in some cases of exophthalmic goitre with double enlargement. This operation consists in exsecting a portion of each lobe. This is too bloody to be recommended. A ligation of both superior thyroid arteries and a later removal of one lobe will accomplish more, and is more readily performed.

Taboulay's operation of exothyreopexy is not to be recommended. The process of healing is too tardy, and the benefit not as assured as by either the ligation of the vessels or the partial removal of the gland. I do not know that this method is being adopted by any other than Jaboulay.

Lastly, I shall mention the operations on the sympathetics. Surgery of the cervical sympathetics had its initiative with Alexander, of Edinburgh, who resected the superior ganglion on both sides for epilepsy. This was in 1889. Jonesco, in Aug., 1896, resected the superior and middle cervical ganglia for Graves' disease, and the operation has since borne his name. A Russian surgeon. by the name of Barocz proposed the operation as early as 1893 . In my one case for exophthalmic goitre the operation was done in two sittings. 'The incision being made along the posterior border of the sternocleidomastoid. It can be readily done under eucain anesthesia.

Whatever the operation performed, general anesthesia should not be used. The inyopathy and the vaso motor disturbance makes it exceedingly dangerous. This caution against general anesthetics holds also where the operation is for some other purpose than to relieve the symptoms of the exophthalmic goitre. Strange to say, the condition which follows operation upon these cases under general anesthesia is alike, whether done for the relief of the goitre or for other purposes, indicating that handling of the gland is not an explanation for it. I recall a case in which.I used general anesthesia in the currettement of a bleeding uterus, following an abortion, in which all other means had failed. For two days following the operation the pulse rate was between 190 and 210. Eventually, she recovered from the immediate danger, only to succumb to an enteric attack later.

An objection to the use of cocain based upon the report of Riviere and Edmunds is not well taken; they assert the symptoms of cocain intoxication correspond to those of Graves' disease. Even if so, I can not agree with those who consider a unity of action in the two cases. However, in using eucain anesthesia, the amount of the drug is too sinall to produce additional intoxication.

'The results from operative treatment of Graves' disease have been, on the whole, gratifying. Naturally, they vary somewhat with different operators, and also with the character of operation. Mortality has been surprisingly low; in 1896 Starr gave a record of 190 cases collected, with a mortality of only 12 per cent. Kinnicut the same year presented the record of 187 cases with 7 per cent. mortality. Schulz records 20 cases without mortality. The most valuable record of the present time comes from Kocher, of Berne, in which he had four deaths in 59 cases operated upon by himself. In these, the operation could not be held entirely responsible. Ligation had in the past a larger per cent. of mortality than thyroidectomy, but there should be no reason for this at the present time. In the group of cases 
I present, the one death was undoubtedly the result of having given a general anesthetic.

The relief of the symptoms of Grares' disease has been gratifying. A fair average for the cures from operative procedures during the last ten years may be stated as 60 per cent.; of decided benefit 15 per cent.; and of deaths and failures, the remaining. In the 7 cases surviving the partial thyroidectomy performed by myself, the symptoms in all practically disappeared. Betterment was noted in all but one within forty-eight hours. The continuation of a high pulse in Mrs. W. was due to the pulmonary complication. Nervousness in each case disappeared almost completely before leaving the hospital, with the exception of the last case operated on but a few days since.

In one of my cases the nerve was injured by being grasped by forceps, and though the ligature was put about the vessel afterward, in such a manner as to avoid including the nerve, the voice was never quite normal afterward. Two of the cases had a slight tetanic convulsion immediately following the operation, but recorered as speedily as the others, without apparent ill effects. Mrs. B. had an interesting condition in that the right lobe of the thyroid was the larger, while the left eye was most protuberant. Exophthalmia in her case disappeared entirely after operation. Case S. S. carried her child to full term under a far more comfortable condition than was possible without relief of the exophthalmic goitre symptoms. After the operation certain symptoms may continue for a longer or shorter time before disappearing. The most persistent of these is the exophthalmia. In my cases ocular co-ordination was one of the first noticeable benefits. The physchic disturbances which follow, I believe, may be attributed to an infection of the wound in the majority of cases. This is illustrated by my last case. Three days after the operation she sat up, declaring herself better than for sometime. Her pulse and nervous symptoms certainly indicated this. On the sixth day she began to complain of pain in the area of the wound, which was the result of a slight inflammatory reaction. After that she became extremely irritable, taking marked dislike for her nurse. In her case the whole of the left thyroid was removed, with the exception of a small portion of the upper end, containing an apparently normal para-thyroid.

The question arises did the presence of the parathyroid produce this excitation, or was it septic? The removal of the para-thyroids in animals gives rise to bymptoms like those of Graves' disease, but I am at a loss in the absence of the thyroid proper to account for the presence of these bodies producing any such effect.

The character of the gland changes differed in the various cases. Vascular degeneration was apparent in all, but in many there were primary conditions not related to the exophthalmic goitre, and in some, undoubtedly secondary changes, consequent upon the marked vascularity of the thyroid.

As time will not permit a discussion of these differences in detail, I shall have to present them in a later paper.

\section{DISCUSSION.}

Dr. W. W. Glant, Denver-I have had no experience, whatever, with the operation for the treatment of exophthalmic goiter. The operation is more particularly appropriate to certain cases of traumatic epilepsy and glaucoma. Kocher, in 200 or 300 operations performed during the last two or three years, has used a solution of cocain. He has abandoned the use of general anesthetics, because of the unsatisfactory results, one of which is vomiting, which may occur during the progress of the operation, and if any surgeon attempts to perform this operation on a reasonablly large tumor, particularly on a vascular one, without due considerati the difficulties and complications that may arise, he is to a rude awakening. I have performed only a few of operations, but $I$ invariably open the capsule. It is easier to nake the incision through the skin, dissect the tumor, and then open the capsule. It is much eas ligate the arteries, and the operation can be done mucb quickly; and this is an operation demanding all po. celerity. I had a case two or three months ago, the lg of these tumors that $I$ have ever removed. It occurte a woman 40 years of age, and tıe tumor had existe twenty years. Whether or not we can explain it, it is that the condition of many of these patients, although ingly good, is not so in reality. They have but little ing power. They succumb to the slightest hemorrbe well as to anesthetics, their. condition becomes alarm times during the most critical period of the operation. opening the capsule I had no difficulty in ligating the thyroid vessels, but in separating the tissues for the su thyroid $I$ opened a sinus with the finger and a blood came out, which, it seemed, was as large as the little It was quickly arrested, and although but a small amoung blood was lost, it was noticed that the patient was. state of collapse. I proceeded with the operation? assistants used restoratives and the patient recovered $q$ and her convalescence was uneventful. I always prepar patient for such an operation. I insist that the patient remain in the hospital for three or four days (or a more) and use $1 / 30$ of a grain of strychnia three times a day. I have found this to be very useful. sary, atropin may be administered before the operat a heart tonic. I have found it very appropriate in cases. The amount of cocain which Kocher uses is a per cent. solution, but I have not employed it because its effect on the heart, especially in large tumors. used chloroform, but fear general anethesia also.

Dr. EMIMET RIXForo, San Francisco-Goiter is which produces fearful suffering to the patient, and we can cure those patients by operation or not; we ar a tremenduous service to them, if we can alleviate symptoms. But the operative treatment is not so sim it may appear. The problem is an extremely difficult Exophthalmic goiter may be said to be of two sorts, p exophthalmic goiter and secondary exophthalmic goiter: the latter I mean those cases in which the disease or symp supervene in the presence of existing goiter, and pro from operative procedure is infinitely better in the class of cases. In these cases there is very often an thyroid adenoma, which is the seat of the goiter. The tion is much simpler in those than in the so-called pr exophthalmic goiter. It simply requires the removing adenoma, if the capsule can be identified. The oper should be undertaken with the greatest caution in those in which the heart shows degeneration. Confidence the greatest value to such a patient, and he should be to rest and become accustomed to the surroundings hospital, mental as well as physical preparation for the being necessary. The greatest danger, as Kocher nitely demonstrated, is the anesthetic. I have greatest trouble from an anesthetic, the heart beating and faster until it reached 200 , then 300 per minute finally became too fast to be counted. These patients $p^{p}$ tremendously. They do not stand antiseptics well, and should be used with the greatest caution. They do not sepsis well and, therefore, the greatest care should b to have a perfect technic. I have operated on four of exophthalmic goiter, protecting the wound by a sterilized cloth around the neck, and held up by at the end of the table, so that the patient cannot hemorrhage, and so that he could not see what was go The sight of the forceps and instruments, etc., increas nervousness of the patient. I employ 1 per cent. a local anesthetic. I prefer to make the transverse where the tumor is not very large, principally becal 
the ${ }^{\circ}$ onmetic effects. Women are much more likely to have mado condition than men, and the transverse incision can be by a very low down and the scar can always be covered the coll of ribbon. The vertical sear always sticks up above gives preferable room and where the tumor is large, it is the spoon operation. I was interested in hearing Dr. Witherenucleating of opening the posterior fascia of the neck and assistang the tumor. Kocher speaks of cocain being of that it In my last case that I operated on I thought of a was so simple that I could remove it without much but pround. I did not draw the gland to the middle line, $80 \mathrm{me}$ rorked from the outside. I passed the ligature around ligaturessels and the man indicated that he could talk. The poice. Was removed and the man has since recovered his certain As to the relief of these exophthalmic symptoms, in one ease thes, it is wonderful and often immediate. I had sages that had been having from fifteen to twenty pasperpiration the bowels a day. She suffered from profuse ing the the sheets had to be changed several times durshe prefert. The patient did not expect to recover; in fact, remopal to die. Within a week from the time of the peight. the thyroid adenoma she had lost thirty pounds in Walk. She had been practically bedridden and unable to the more than half a block before the operation, but within miles months thereafter she had ridden a bicycle twenty DR. J. S rough country road.

delermine Sheton Honslex, El Paso, Texas-I think we can not its pathe the proper surgical treatment of this condition until theories.ogy has been more definitely settled. There are two inating; one is that the disease is due to morbid impulses orig${ }^{0} u_{B} \mathrm{By}_{\mathrm{st}}$ the medulla and sent out over the sympathetic nerv. these imptem, the excess of thyroid secretion being due solely to by ap inulses. The other theory is, that the disease is caused the excess of thyroid secretion in the blood, which acts on goiter the system. We know that in cases of exophthalmic secretion. the is nearly always present an excess of thyroid Beneh. However, this is not universally true, for some the the surgeons have observed this disease in cases in which and in groid gland had been previously removed by operation ot la cases in which it was apparently congenitally absent, or been so small as to escape detection. These facts have delphia, well brought out by Dr. Alfred Gordon, of Philafer sears a paper in the Philadelphia Medical Journal a ton iears ago. If this first theory is correct, Jonnesco's operainterpupts unestionably the correct procedure, as it permanently Wupts these impulses by taking out all of the cervical Jornesco's ganglia. If, however, the second theory is correct, Procedurs operation is clearly inapplicable, and the only logical tons are is excision of the thyroid gland. As these two operaopposed founded on pathologic theories that are diametrically Thininatel each other, it does not seem proper to use indisThoid, deper the Jonnesco operation or excision of the sipen, depending on whichever may be easier performed in a Abouse.

Boiter three years ago I operated on a case of exophthalmic idease, having all the classical signs and symptoms of that cervical I did a partial Jonnesco operation, removing the antended sympathetic ganglia on the right side of the neck. I condition removing them on the left side also, but the patient's ${ }^{8} i_{d e}$ forbade it, as her pulse was about 200 when the right of finished. The operation was reported in the Annals at gery about eight months later, as it was one of the ooiter had in which the Jonnesco operation for exophthalmic the had been done in America. At the time of the report, bained improved wonderfully; pulse was 100 and she had throid, weight more than 30 pounds. The swelling in the tioner, had not perceptibly decreased. Soon after ope candite patient began to get worse, and is now in the Peration she was in when first operated on. A second ofe, thoug removal of the ganglia on the left side of the of though proposed, has been rejected. It seems that cases oppothalmic goiter may be cured, or at least relieved and poid, by either Jonnesco's operation or excision of the operations which are founded on entirely different pathologic theories. It has occurred to me, in view of the improvement and subsequent relapse of my case and after reading the literature on the subject, that operation may have the same effect in exophthalmic goiter that is attributed to trephining in epilepsy. In other words, any operative procedure that is sufficiently severe to affect profoundly the nervous system, may result in relief of this disease, just as epilepsy is often apparently cured by simply trephining.

Dr. T. C. Wituerspoon, St. Louis-In regard to the indication for operation in exophthalmic goiter I believe that these cases should first be subjected to internal medication and then, if that fails, we should operate. In regard to the last Jonnesco operation I am not in a position to express an opinion on it. I was not gratified by the results obtained in these cases. I have not done it in exophthalmic goiter but once, but $I$ have tried it three times in epilepsy and in none of the three cases did I secure results that were very gratifying. The one important thing that I want to speak of is the giving of a general anesthetic to these patients. We should not forget that when they are operated on for removal of the thyroid or for any surgical condition whatever they suffer tremendously from the effects of a general anesthetic. I remember a case I had in which the pulse was from 140 to 150 , and I gave chloroform to allow of uterine curettement, and her pulse ran up to between 190 and 220 , but she ultimately recovered from this condition. 'A general anesthetic is dangerous, and those who operate under general anesthesia are going to obtain poor results. In the next place those gentlemen who prefer simply to deal with the gland by primarily shelling it out $I$ think are going to regret it some day. You should tie the-blood-vessels early. There is but one way to tie them, and that is to get back of the fascia. If you get back of the fascia above the gland and run your finger behind the gland you can separate the carotid sheath and vessels from the gland, and render ligation and separation of the structures easy. I had one case in which a portion of the gland had grown down back of the sternum and another in which the gland was very deep in the neck, so that they are very different in shape and can not be dealt with alike.

\section{PATHOLOGY AND TREATMENT OF SMALLPOX.}

\section{AN ANALYSIS OF OYER TWO THOUSAND CASES AND OF FIFTY AUTOPSIES.*}

NELSON D. BRAYTON, A.M., M.D.

Assistant to the Chair of Dermatology, Syphllology and Clinical Medicine and Demonstrator of Bacteriology in the Medical College of Indiana.

\section{INDIANAPOLIS.}

\section{CI.ASSIFICATION.}

It is not my intention to discuss in detail the problem of the pathology of smallpox, but only to utilize in so far as practical the knowledge acquired by personal observation and autopsy in the treatment of this disease. The subject of the pathology of smallpox is in itself one of large scope and bearing, and worthy of single effort. Inasmuch as the tendency of medicine at the present day is to build the treatment of disease on the knowledge acquired of anatomic defects, it seems consistent to group the two headings.

The pathology of smallpox comprises at least three distinct considerations: First, the conditions arising from the poisonous influences of the variolous contagion itself (mainly purely speculative and relating to black smallpox). Second, the conditions arising from the maturation stage; and third, the incidental complications and sequelæ. In the latter class are considered boils, abscesses, phlegmonous conditions, erysipelas, the eye symptoms and the accidents to pregnancy.

* Presented at the Fifty-fourth Annual Session of the American Medical Assoclation, in the Section on Cutaneous Medicine and Surgery, and approved for publication by the Executive Committee : Drs. H. W. Stelwagon, W. L. Baum and J. A. Fordyce. 